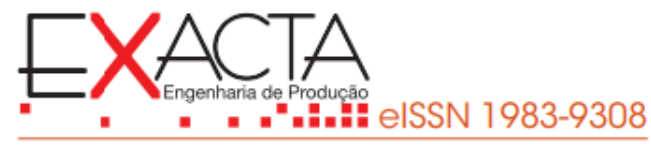

\title{
IMPLEMENTAÇÃO DA MODELAGEM DA INFORMAÇÃO DA CONSTRUÇÃO (BIM) EM PROJETOS PESQUISA E PROPOSTA DE MELHORIA NO CONTEXTO DA GOVERNANÇA, RISCO E CONFORMIDADE (GRC)
}

\section{BUILDING INFORMATION MODELING (BIM) IMPLEMENTATION IN ENGINEERING PROJECTS RESEARCH AND PROPOSAL IN GOVERNANCE, RISK MANAGEMENT AND COMPLIANCE (GRC) CONTEXT}

Recebido em: 13 dez. 2019

Aprovado em: 05 dez. 2020

Versão do autor aceita publicada online: 05 ago. 2020

Publicado online: 06 jul. 2021

Como citar esse artigo - American Psychological Association (APA):

Oliveira, E. V., \& Zaidan, F. H. (2022, out./dez.). Implementação da modelagem da informação da construção (BIM) em projetos pesquisa e proposta de melhoria no contexto da governança, risco e conformidade (GRC). Exacta. 20(4), 810-831. https://doi.org/10.5585/exactaep.2022.16216.

Submeta seu artigo para este periódico 色

Dados Crossmark 


\title{
IMPLEMENTAÇÃO DA MODELAGEM DA INFORMAÇÃO DA CONSTRUÇÃO (BIM) EM PROJETOS PESQUISA E PROPOSTA DE MELHORIA NO CONTEXTO DA GOVERNANÇA, RISCO E CONFORMIDADE (GRC)
}

\author{
BUILDING INFORMATION MODELING (BIM) IMPLEMENTATION IN \\ ENGINEERING PROJECTS RESEARCH AND PROPOSAL IN GOVERNANCE, RISK \\ MANAGEMENT AND COMPLIANCE (GRC) CONTEXT.
}

Emerson Viana de Oliveira ${ }^{1}$

Fernando Hadad Zaidan ${ }^{2}$

\author{
${ }^{1}$ Mestre \\ Instituto de Educação Tecnológica - IETEC \\ Belo Horizonte, Minas Gerais - Brasil \\ emerson.viol@gmail.com \\ ${ }^{2}$ Doutor \\ Instituto de Educação Tecnológica - IETEC \\ Belo Horizonte, Minas Gerais - Brasil \\ fhzaidan@gmail.com
}

Recebido em: 13 dez. 2019

Aprovado em: 05 dez. 2020
Resumo: O objetivo desta pesquisa é identificar os ganhos com o desenvolvimento e a implementação de um modelo de compatibilização entre projetos, planejamento e custos na ótica do building information modeling (BIM), em empresas de engenharia, com estruturas de governança, riscos e conformidade (GRC), que priorizam a melhoria nos resultados corporativos. A identificação e eliminação de conflitos e interferências de espaço e tempo durante a construção é apontada como maior benefício do BIM. A integração e a comunicação entre todos os envolvidos no projeto também têm seu grau de importância evidenciado e a redução do esforço na visualização e interpretação mental do planejamento é destaque em termos de aplicabilidade dos projetos. Como conclusão, a combinação das dimensões 3D, 4D e 5D do BIM, em empresas de engenharia que adotarem políticas estruturadas de GRC, garante impactos positivos nos resultados dos empreendimentos. Recomenda-se este estudo para os profissionais que se interessem pela inovação e ampliação dos conhecimentos dos benefícios da implementação do BIM, bem como perceber como as políticas de GRC podem ser avaliadas.

Palavras-chave: Modelagem da informação da construção. BIM. Governança. Gestão de risco. Conformidade.

Abstract: This study investigated aims identify the gains with the development and implementation of a model of compatibility between projects, planning and costs from the perspective of Building Information Modeling (BIM), in engineering companies, with governance structures, risks and (GRC), which prioritize improvement in corporate results. The identification and elimination of possible conflicts and interference of space and time during construction is pointed out as the greatest benefit, and the integration and communication between all involved in the project has a greater level of importance and the reduction of effort in the visualization and mental interpretation of the planning is highlighted in terms of applicability of the projects. In conclusion, the combination of BIM's 3D, 4D and 5D dimensions in engineering companies that adopt structured GRC policies ensures positive impacts on project results. This study is recommended for managers of engineering companies interested in innovation and broadening knowledge of the benefits of implementing BIM, as well as understanding how GRC policies can be evaluated.

Keywords: Building Information Modelling. BIM. Governance. Risk management. Compliance. 


\section{Introdução}

Consequentemente, em tempos de crise, toda a cadeia de serviços atrelada aos investimentos de engenharia, como estudos de viabilidade, projetos, supervisão, logística, estruturação financeira, dentre outros, são afetados e forçados ao redimensionamento estrutural de suas organizações. Isso ficou mais notório ainda no Brasil e agravado nas últimas décadas com a Operação Lava Jato (OL), conduzida pela Polícia Federal brasileira, que, em 2008, começou a investigar esquemas de corrupções entre empresários e políticos na Petrobrás e, como consequência, o setor de engenharia brasileira também passou a ser penalizado por escândalos e pelo seu histórico de corrupção atrelado à grande dependência das demandas governamentais.

O respeito às leis e a necessidade de práticas anticorrupção são princípios que estão no topo das atenções e todos sabem que é um caminho sem volta, o qual exige políticas e formas cada vez mais sofisticadas de gestão e aderências aos códigos de ética. Tudo isso tem levado as empresas bem estruturadas no ramo da engenharia à busca de novas formas de atuação no mercado, como a diversificação da carteira de obras, que antes focava em obras públicas e hoje visa à aquisição de contratos com a iniciativa privada, incorporações, financiamentos estruturados e concessões ferroviárias, rodoviárias, energética, portuária, dentre outros.

Como consequência desse cenário de diversidade e competitividade, as empresas de engenharia têm buscado estruturas organizacionais mais enxutas e com gestores polivalentes. Segundo Rodrigues et al. (2018), no campo operacional se observa a implementação de programas de reduções de custos, focados em melhorias contínuas de produtividade, confiabilidade de suas ações, redução de custos, melhorias operacionais, layouts e Lean construction" ${ }^{1}$ Sendo assim, um "conjunto de boas práticas que, juntamente com um modelo de gestão, trazem grandes benefícios às indústrias, principalmente sob a ótica de redução de custos" (TEIXEIRA; MELIM, 2014, p. 1). Como consequência, as empresas de engenharia vêm buscado inovar e ousar nas práticas de governança corporativa, gestão de planejamento, riscos e conformidade.

Um modelo adotado nessas novas práticas tem sido a implementação do building information modeling ${ }^{2}$ (BIM). Segundo Eastman et al. (2008), o BIM é uma proposta de modelagem associada aos processos de produzir, comunicar e analisar o projeto de uma edificação. A proposta deste estudo é indicar as vantagens e possíveis deficiências em um modelo de GRC e, adicionalmente, apontar as vantagens da adoção do BIM como melhoria de processos

\footnotetext{
${ }^{1}$ Lean construction é a aplicação da mentalidade enxuta implementada pelo sistema Toyota de produção. Auxilia na identificação e eliminação do desperdício, melhora a qualidade e permite reduzir o tempo e o custo de produção.

${ }^{2}$ Modelagem da informação da construção.
} 
e sistemas de integração entre projeto, planejamento e custos em cada empreendimento. Para tanto, deverão ser indicadas as melhorias nos modelos de GRC das empresas de engenharia, com a implementação do BIM e como a integração das metodologias poderá impactar significativamente em todos os negócios e na organização como um todo, o que poderá resultar em melhorias e aumento do valor agregado das empresas.

Com este estudo, é possível apontar e discutir as possíveis vantagens da adoção do modelo BIM em empresas de engenharia, com sistemas de GRC implementados. É neste contexto que o objetivo principal é propor melhorias nos resultados de gestão de projetos em empresas de engenharia a partir da implementação da modelagem de projetos por meio da compatibilização entre suas especialidades com o BIM 3D, planos de execução com o BIM 4D e custos na ótica do BIM 5D, segundo as políticas de governança, riscos e conformidade. Diante deste objetivo, apareceram como objetivos secundários:

a) Levantar métodos e procedimentos de um sistema de modelagem e compatibilização entre projetos, planejamento e custos (BIM) e governança, gestão de risco e conformidade adotados pelas empresas de engenharia;

b) Identificar os principais indicadores de performance que impactam nos resultados das empresas;

c) Citar os impactos positivos nos resultados de empresas com sistemas de modelagem e compatibilização entre projetos, planejamento e custos na ótica do BIM, governança, gestão de risco e conformidade eficazes;

d) Indicar como a implementação do BIM em empresas de engenharia pode influenciar a conquista da excelência de projetos, compatibilização e eficácia no planejamento e alcance das metas de prazo e melhoria em resultados econômicos e financeiros.

\section{Referencial teórico}

\subsection{Novos rumos na indústria da construção: Indústria 4.0 e o BIM}

De acordo com Formoso (2001), as empresas têm sido estimuladas a buscar melhores níveis de desempenho por meio de investimentos em gestão e tecnologia da produção. Com o avanço da tecnologia surgem novos parâmetros de controle e obtenção de resultados que obrigam as empresas de engenharia a adotar novos modelos de gestão e de operação, inclusive a capacitação de seus altos executivos e dos profissionais de ponta.

Para Ramos, Rodrigues e Melo (2018), a transformação digital da era 4.0 está mudando o setor de construção, porém, de forma muito lenta. De acordo com os autores, o BIM por ser considerado atualmente como a aplicação mais difundida na construção civil a nível mundial da 
indústria 4.0. Neste contexto, o BIM é considerado como a tecnologia com maior probabilidade de aplicação e impacto futuro na construção. E, como resultado, toda essa revolução traduz-se em maior flexibilidade, velocidade de produção, qualidade do produto, produtividade, participação do cliente, além do surgimento de novos modelos de negócio.

\subsection{Building information modeling}

O BIM é uma prática inovadora no Brasil e nas empresas de engenharia a qual envolve planejamentos e custos, pois "permite a integração entre os projetos na sua elaboração utilizando-se do ambiente tridimensional, para corrigir incompatibilidades desde a sua concepção" (MENEGARO; PICCININI, 2017, p. 2). Assim, por meio da modelagem tridimensional, torna-se possível a visualização dos projetos, o que contribui para a redução dos erros e do tempo de execução das obras, pois o protótipo se associa aos processos de produzir, comunicar e analisar o projeto de uma edificação.

Rodrigues et al. (2018, p. 304) apontam que "a principal diferença entre um software de modelagem 3D e um software BIM é a capacidade de gerar objetos paramétricos". E, nesse sentido, "[...] a parametricidade permite gerar objetos editáveis, que podem ser alterados automaticamente e suportar a plataforma BIM" (RODRIGUES et al., 2018, p. 304). De acordo com os autores, sem ter essa capacidade, o software é considerado somente um modelador tridimensional. Nesse contexto, o Revit, da Autodesk, é o principal software de modelagem BIM 3D, utilizado no mundo inteiro.

A adoção da metodologia BIM permite trocas semânticas entre as definições, compatibilizações de projeto e um modelo de geração de cronogramas, com o BIM 4D $D^{3}$, e custos, com o BIM 5D4. Ferramentas como o Navisworks, Synchro e Vico Office 4D Manager podem promover essa integração BIM 4D, pois permitem visualizar a evolução da obra e a comparação entre o previsto e o realizado de forma mais realista, ou seja, transformam números e barras em uma representação mais amigável. Para o BIM 5D, o Navisworks e o Vico Software proporcionam o levantamento de quantitativos para a geração de orçamentos e a atribuição do valor total a cada componente de forma prática.

\footnotetext{
${ }^{3}$ De acordo com Rodas (2015), a dimensão conhecida como BIM 4D refere-se ao tempo, que é capaz de oferecer um planejamento temporal, possibilitando acompanhar a edificação ao longo de seu ciclo de vida.

${ }^{4}$ De acordo com Rodas (2015), o BIM 5D é associado a estimativas de custos, designando ao modelo a capacidade de atribuir valores aos elementos do projeto.
} 


\subsection{Sintese dos trabalhos relevantes}

\subsubsection{Avaliação de estratégias para representação e análise do planejamento e controle de obras} utilizando modelos BIM 4D

O estudo, realizado por Brito e Ferreira (2015), teve como objetivo avaliar estratégias para representação e análise do planejamento e controle de obras mediante a utilização dos modelos BIM 4D na visão de profissionais da construção civil. As abordagens do questionário da pesquisa permitiram mapear a diferenciação das atividades internas, alternativas de monitoramento do avanço físico por meio de simulação dos cronogramas planejados e realizados, além de avaliação sobre adoção de modelos 4D.

O artigo contribui para conhecimento da visão da construção civil brasileira ao apresentar suas potencialidades, estratégias para representação e análise, bem como as possibilidades de adoção dos modelos BIM 4D. Os resultados da pesquisa indicam que a integração e comunicação entre os envolvidos no projeto e a redução do esforço na visualização demonstram o poder de integração e visualização, o que pode facilitar a compatibilização dos níveis de planejamento.

\subsubsection{Aplicação da metodologia BIM no processo de projeto, com foco em compatibilização}

O artigo de Menegaro e Piccinini (2017) aborda a aplicação dos conceitos da metodologia BIM ao simular a elaboração dos projetos de forma integrada, no intuito de encontrar as incompatibilidades de projeto durante o processo com seus respectivos registros. $\mathrm{O}$ trabalho propõe um fluxograma de processo de projeto simplificado baseado no conceito da metodologia BIM, com geração de relatório completo de incompatibilidades encontradas. A proposta é eficaz para prever incompatibilidades antecipadamente, pois possibilita que estas sejam detectadas desde a modelagem até a fase de obra.

A metodologia mostrou-se eficaz com a concepção dos projetos dentro da tecnologia BIM de forma integrada. Os modelos de análises propostos permitem detectar incompatibilidades de projeto e, com isso, obter a maximização dos ganhos tanto em projetos quanto na fase de construção.

\subsubsection{Modelo conceitual para GRC integrado}

Os modelos destacam as quatro principais funcionalidades da GRC na perspectiva dos autores: gestão de auditorias, gestão de políticas, gestão de questões e gestão de riscos. A governança institucional se refere ao modelo de gestão definido pela alta direção que funda e/ou administra uma corporação, ou seja, se relaciona à "pessoa ou grupo de pessoas que dirige e controla uma organização no nível mais alto" (ABNT, 2018, p. 27). De acordo com a ABNT (2018), 
são princípios de uma boa governança: a ética, a honestidade, a integridade, a transparência e a sustentabilidade (Figura 1):

Figura 1

Princípios de uma Boa Governança

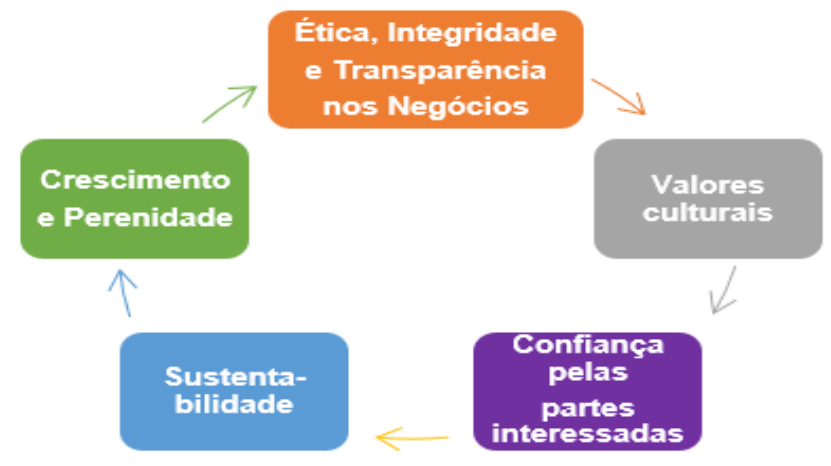

Fonte: ABNT 2018.

Segundo Vicente e Silva (2011), a governança é responsável pela supervisão da gestão de riscos e da conformidade. Uma gestão de riscos bem estruturada deve ser alinhada e ligada à governança e conformidade a fim de obter informações vantajosas para seu processo de gestão de riscos. $\mathrm{O}$ artigo propõe um conjunto de conceitos abrangendo o domínio GRC. Apresentam-se as principais funções de governança, risco e conformidade e suas associações, resultando em um modelo conceitual de referência para o GRC integrado.

\subsubsection{Por que os "bons" gerentes fazem más escolhas éticas}

O estudo de Gellerman (1986) demonstra a triste realidade do passado em que muitos gerentes eram promovidos com base em resultados "ótimos" obtidos de maneiras desonestas. Seu estudo sobre os motivos pelos quais "bons" gerentes fazem más escolhas éticas, delineou quatro tipos de razões comuns que podem levar à má conduta: 1) uma crença de que a atividade está dentro de limites éticos e legais razoáveis, isto é, que não é "realmente" ilegal ou imoral; 2) a crença de que a atividade é do interesse do indivíduo ou da corporação, e de alguma forma, seria obrigado a realizar a atividade; 3) a crença de que a atividade é "segura" porque nunca será descoberta ou divulgada; a clássica questão de crime e punição da descoberta; 4) a crença de que, como a atividade ajuda a empresa, esta tolera e protege a pessoa que se envolve nela.

O estudo indica a necessidade de as empresas não serem enganadas pela falta de integridade de seus gerentes, que devem se preocupar não só com os resultados, mas com o modo como tais resultados são obtidos. Ao final, cabe à alta gerência enviar uma mensagem clara e pragmática a todos os funcionários de que a boa ética ainda é a base de bons negócios. 
3 Metodologia

A metodologia deste estudo contempla a análise do problema de pesquisa, por meio do método design science research (DSR), onde "pesquisas que se dedicam à construção de artefatos devem poder se sustentar como válidas cientificamente com uma abordagem metodológica rigorosa e apropriada" (LACERDA et al., 2013, p. 743). Para a identificação dos artefatos, o DSR permite o desenvolvimento do conhecimento prescritivo que possibilita conceber e desenvolver artefatos que estabelecem relação teórica/prática, cujas pesquisas possam sustentar soluções para os problemas reais existentes.

Neste estudo se pretende atingir a conscientização a partir do conhecimento e delimitação do problema, o que possivelmente irá gerar mais de um artefato e, consequentemente, múltiplas soluções em virtude de sua localização. Para a validação do problema desta pesquisa (FIGURA 2), pretende-se buscar o conhecimento a partir de duas etapas iniciais:

(A) Pesquisar e analisar empresas que possuem sistemas de GRC estabelecidos, independentemente da eficiência na aplicação prática no dia a dia e na cadeia de decisões estratégicas;

(B) Identificar as melhores práticas, utilizando o design science, com foco em identificar as empresas que têm melhor performance em termos de GRC.

Figura 2

Construção das Classes de Problemas de Pesquisa

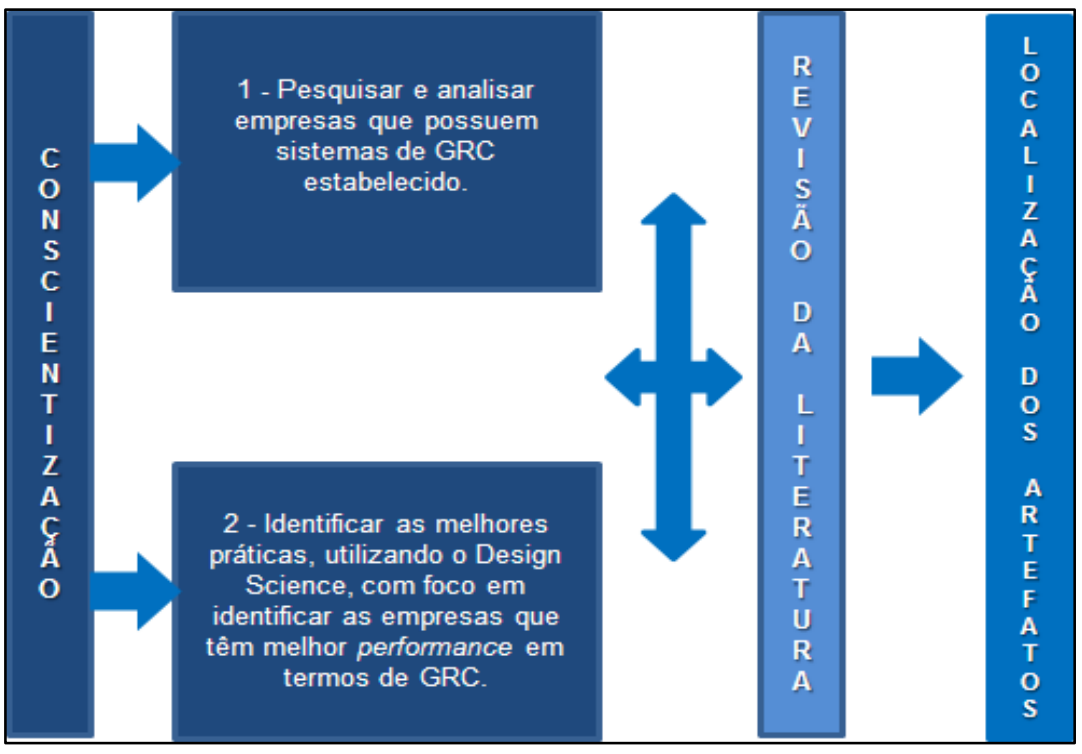

Fonte: AUTOR, 2019. 
A busca pelo aprofundamento sobre o conhecimento do GRC e da identificação de melhores práticas em engenharia serão as premissas iniciais deste estudo, as quais trarão subsídios para a delimitação de uma empresa que aceite a adoção do BIM em termos de compatibilização de projetos (3D), planos de execução das atividades e metas de prazos (4D) e orçamentos e consolidação dos custos (5D).

Ao determinar os artefatos (seleção de uma empresa), este estudo pretende avançar na aplicação e busca de soluções em mais três etapas subsequentes:

a) Apontar uma empresa dotada de melhores práticas para a adoção do BIM;

b) Elencar as possíveis melhorias de processos a serem obtidas com a adoção do BIM em termos de compatibilização de projetos (3D), planejamento das atividades e metas de prazos (4D) e orçamentos e consolidação dos custos (5D);

c) Associar as melhorias e ganhos possíveis de se obter com a aplicação do BIM à melhoria de resultados em uma empresa com sistemas de GRC eficientes.

\subsection{Revisão sistemática da literatura}

A revisão sistemática da literatura (RSL) foi utilizada para possibilitar a identificação e análise de dados por meio de uma seleção criteriosa de documentos para referencial teórico. A RSL possibilita "a descrição detalhada dos resultados e conclusões, para que haja confiabilidade e qualidade científica no desenvolvimento e disseminação das pesquisas" (CERRAO; CASTRO; JESUS, 2018, p. 105). Nesse sentido, a Figura 3 demonstra os critérios adotados para a RSL deste estudo para selecionar os artigos correlatos e as citações-referência. 
Figura 3

Processo Executado na RSL

\section{Pergunta científica:}

Como a implementação do BIM em empresas de engenharia com governança, gestão de riscos e conformidade bem estruturados podem melhorar seus resultados corporativos?
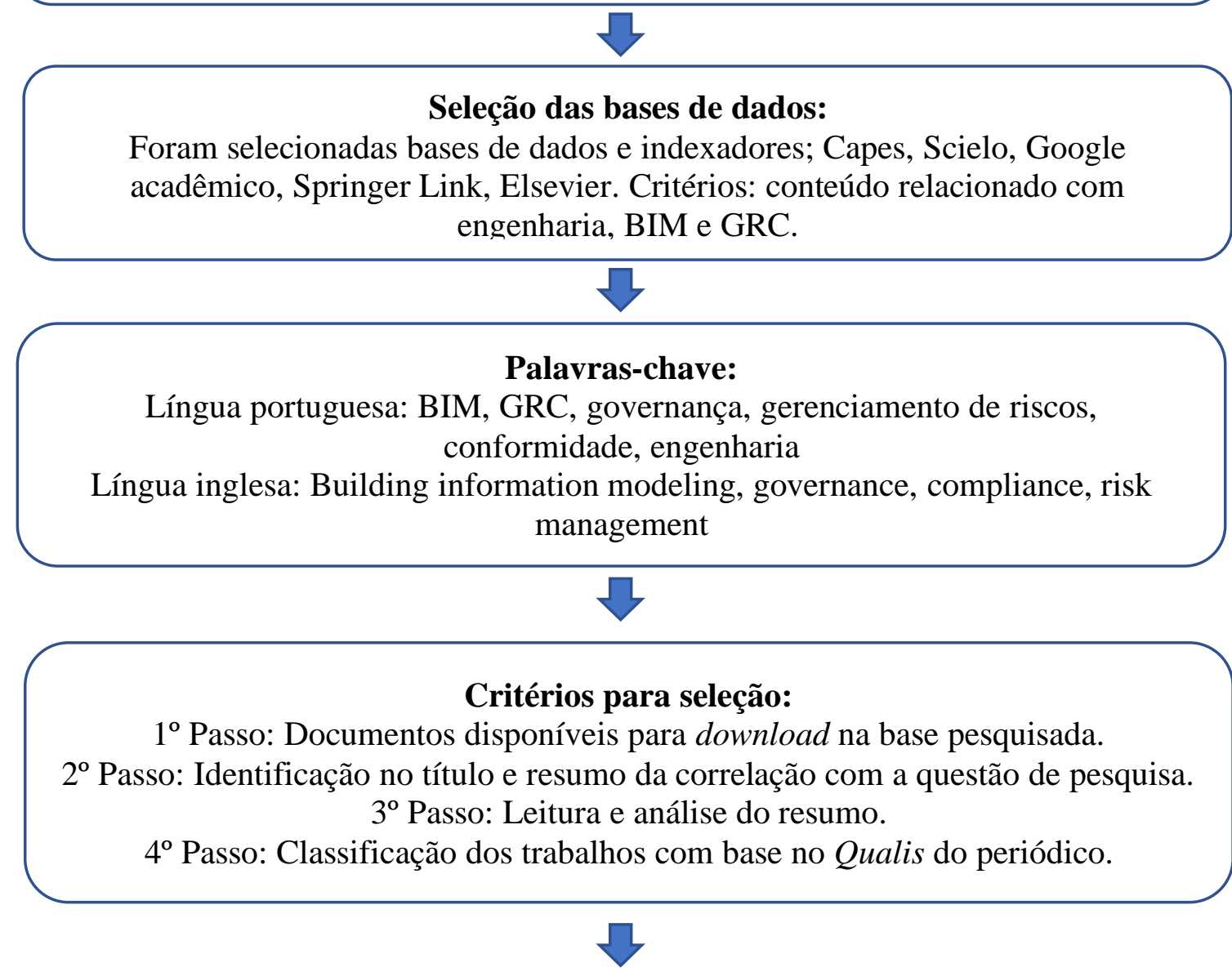

\section{Análise dos documentos e aplicação dos critérios}

Após aplicação dos critérios, dos 2.462.816 documentos encontrados, foram selecionados 56 documentos que apresentam o estado da arte da pesquisa científica neste contexto e serviram como referência neste trabalho. Desses documentos foram utilizados como trabalhos correlatos três artigos científicos e um documento secundário publicado em revista internacional.

Fonte: AUTOR, 2019.

A partir desses levantamentos, optou-se pela seleção de três artigos científicos correlatos que se referiam à integração do modelo BIM e ao estudo de modelo de governança, gestão de risco e conformidade. Além de um documento secundário para melhor compreensão das escolhas éticas corporativas. Quadro 1 apresenta os artigos selecionados. 


\section{Quadro 1}

Lista de Trabalhos Correlatos

\begin{tabular}{|c|c|c|c|c|c|}
\hline Seleção & Ano & Assunto & Título & Autor principal & Qualis \\
\hline \multirow{3}{*}{ Principal } & 2015 & BIM & $\begin{array}{l}\text { Avaliação de estratégias para representação e análise } \\
\text { do planejamento e controle de obras utilizando } \\
\text { modelos BIM 4D }\end{array}$ & $\begin{array}{l}\text { Douglas } \\
\text { Malheiro de } \\
\text { Brito }\end{array}$ & $\mathrm{A} 2$ \\
\hline & 2017 & BIM & $\begin{array}{l}\text { Aplicação da metodologia BIM (Building Information } \\
\text { Modeling) no processo de projeto, com foco em } \\
\text { compatibilização }\end{array}$ & $\begin{array}{l}\text { Bruna Ferreira } \\
\text { Menegaro }\end{array}$ & B1 \\
\hline & 2011 & GRC & $\begin{array}{l}\text { A conceptual model for integrated governance, risk } \\
\text { and compliance }\end{array}$ & Pedro Vicente & IST Lisboa \\
\hline Secundário & 1986 & GRC & Why 'good' managers make bad ethical choices & $\begin{array}{l}\text { Saul W. } \\
\text { Gellerman }\end{array}$ & $\begin{array}{l}\text { Literature } \\
\text { in } \\
\text { Bioethics }\end{array}$ \\
\hline
\end{tabular}

Fonte: AUTOR, 2019.

\section{Apresentação da pesquisa}

A pesquisa realizada se dividiu em duas etapas: a primeira voltada para aprofundar o conhecimento do GRC e a identificação de melhores práticas nas empresas de engenharia selecionadas; e a segunda relacionada à aplicabilidade do BIM e de seus benefícios.

\subsection{A pesquisa em GRC}

Para atingir os objetivos deste estudo procurou-se entender o grau de maturidade em GRC das empresas de engenharia durante a execução do ciclo regulador da DSR. Para tanto, inicialmente se optou por realizar uma pesquisa de caráter exploratório para aprofundar o conhecimento e, na sequência, realizou-se a coleta de dados nos artefatos selecionados.

Mediante os questionamentos que surgiram após a fase de conscientização, optou-se pela construção do instrumento de coleta de dados de caráter investigativo, com o propósito de levantar as informações necessárias para dar respostas à aplicabilidade e ao grau de maturidade em GRC nas empresas (artefatos) selecionadas. O primeiro passo foi desenvolver as questões da pesquisa em blocos: 1) governança; 2) gestão de riscos e 3) conformidade (compliance). Por meio da construção do questionário objetivou-se medir os procedimentos e as políticas adotadas, avaliar o grau de maturidade dos artefatos em GRC, desmembrando as informações por classe de gestão para, posteriormente, conhecer as melhores práticas de GRC.

Na sequência, os questionários foram elaborados na plataforma SurveyMonkey, com questões que se relacionam aos objetivos estabelecidos, a utilização do DSR e de algumas das 
técnicas definidas por Whittemore, Chase e Mandle (2001). Os Apêndices A, B e C apresentam as questões que foram consideradas na pesquisa.

\subsubsection{GRC}

\subsubsection{Governanca}

Os resultados das pesquisas relacionados com os critérios de governança dentro das organizações estão relacionados na Tabela 1.

Tabela 1

Questionário Sobre Governança

\begin{tabular}{|c|c|c|c|c|c|c|c|}
\hline \multicolumn{2}{|r|}{ Governança: questões relacionadas } & $\begin{array}{c}\text { Inexistent } \\
\mathrm{e}\end{array}$ & $\begin{array}{l}\text { Soment } \\
\text { e em } \\
\text { algumas } \\
\text { situaçõe } \\
\text { s }\end{array}$ & $\begin{array}{l}\text { Em alguns } \\
\text { departamento } \\
\text { s da } \\
\text { organização }\end{array}$ & $\begin{array}{l}\text { Em vários } \\
\text { departamento } \\
\text { s da } \\
\text { organização }\end{array}$ & $\begin{array}{l}\text { Em toda a } \\
\text { organização }\end{array}$ & Média \\
\hline \multirow[b]{2}{*}{1} & \multirow{2}{*}{$\begin{array}{l}\text { Existem normas de governança e } \\
\text { orientações sobre sua } \\
\text { aplicabilidade na empresa? }\end{array}$} & 0 & 0 & 0 & 0 & 7 & \multirow[b]{2}{*}{5,00} \\
\hline & & $0,0 \%$ & $0,0 \%$ & $0,0 \%$ & $0,0 \%$ & $100,0 \%$ & \\
\hline \multirow[b]{2}{*}{2} & \multirow{2}{*}{$\begin{array}{l}\text { A implantação das normas de } \\
\text { governança na empresa foi } \\
\text { testada antes de ser implantada? }\end{array}$} & 0 & 0 & 0 & 1 & 6 & \multirow[b]{2}{*}{4,86} \\
\hline & & $0,0 \%$ & $0,0 \%$ & $0,0 \%$ & $14,0 \%$ & $86,0 \%$ & \\
\hline \multirow[b]{2}{*}{3} & \multirow{2}{*}{$\begin{array}{l}\text { Existem normas e orientações } \\
\text { para a inclusão desses aspectos- } \\
\text { chave nos programas de apoio ao } \\
\text { desenvolvimento dos gestores? }\end{array}$} & 0 & 1 & 0 & 1 & 5 & \multirow[b]{2}{*}{4,43} \\
\hline & & $0,0 \%$ & $14,3 \%$ & $0,0 \%$ & $14,3 \%$ & $71,4 \%$ & \\
\hline \multirow[b]{2}{*}{4} & \multirow{2}{*}{$\begin{array}{l}\text { Existem políticas, programas de } \\
\text { código de ética e de conduta, } \\
\text { canais de comunicação internos } \\
\text { e de denúncia, ouvidoria e } \\
\text { avaliação da aderência à } \\
\text { integridade e aos valores éticos? }\end{array}$} & 0 & 0 & 0 & 4 & 3 & \multirow[b]{2}{*}{4,43} \\
\hline & & $0,0 \%$ & $0,0 \%$ & $0,0 \%$ & $57,1 \%$ & $42,9 \%$ & \\
\hline \multirow[b]{2}{*}{5} & \multirow{2}{*}{$\begin{array}{l}\text { Os responsáveis pela governança } \\
\text { e a alta administração utilizam } \\
\text { instâncias internas (p. ex. } \\
\text { comitês de segurança, riscos e } \\
\text { controles, auditoria, } \\
\text { coordenação de gestão de riscos } \\
\text { etc. e outras medidas para apoiar } \\
\text { suas responsabilidades de } \\
\text { governança de riscos? }\end{array}$} & 0 & 0 & 2 & 4 & 1 & \multirow[b]{2}{*}{3,86} \\
\hline & & $0,0 \%$ & $0,0 \%$ & $28,6 \%$ & $57,1 \%$ & $14,3 \%$ & \\
\hline \multirow[b]{2}{*}{6} & \multirow{2}{*}{$\begin{array}{l}\text { Existe monitoramento regular de } \\
\text { indicadores-chave de risco e de } \\
\text { desempenho nos seus processos } \\
\text { de governança e gestão? }\end{array}$} & 0 & 0 & 0 & 3 & 4 & \multirow[b]{2}{*}{4,57} \\
\hline & & $0,0 \%$ & $0,0 \%$ & $0,0 \%$ & $42,9 \%$ & $57,1 \%$ & \\
\hline \multirow{2}{*}{7} & \multirow{2}{*}{$\begin{array}{l}\text { São feitas auditorias internas e } \\
\text { externas para certificar que a } \\
\text { administração tem processos }\end{array}$} & 0 & 0 & 1 & 3 & 3 & \multirow{2}{*}{4,29} \\
\hline & & $0,0 \%$ & $0,0 \%$ & $14,3 \%$ & $42,9 \%$ & $42,9 \%$ & \\
\hline
\end{tabular}


Oliveira, E. V., \& Zaidan, F. H. (2022, out./dez.). Implementação da modelagem da informação da construção (BIM) em projetos pesquisa e proposta de melhoria no contexto da governança, risco e conformidade (GRC)

\begin{tabular}{|c|c|c|c|c|c|c|c|}
\hline \multicolumn{2}{|r|}{ Governança: questões relacionadas } & $\begin{array}{l}\text { Inexistent } \\
\mathrm{e}\end{array}$ & $\begin{array}{l}\text { Soment } \\
\text { e em } \\
\text { algumas } \\
\text { situaçõe } \\
\text { s }\end{array}$ & $\begin{array}{c}\text { Em alguns } \\
\text { departamento } \\
\text { s da } \\
\text { organização }\end{array}$ & $\begin{array}{c}\text { Em vários } \\
\text { departamento } \\
\text { s da } \\
\text { organização }\end{array}$ & $\begin{array}{l}\text { Em toda a } \\
\text { organização }\end{array}$ & Média \\
\hline \multirow[b]{3}{*}{8} & $\begin{array}{l}\text { eficazes de gerenciamento de } \\
\text { riscos e controle? }\end{array}$ & & & & & & \\
\hline & A equipe de auditoria detém as & 0 & 0 & 3 & 4 & 0 & \\
\hline & $\begin{array}{l}\text { competências necessárias para } \\
\text { abordagem sistemática ao } \\
\text { avaliar e melhorar a eficácia dos } \\
\text { processos de gerenciamento de } \\
\text { riscos, controle e governança? }\end{array}$ & $0,0 \%$ & $0,0 \%$ & $42,9 \%$ & $57,1 \%$ & $0,0 \%$ & 3,57 \\
\hline \multirow{3}{*}{9} & $\begin{array}{l}\text { Existe descrição concisa dos } \\
\text { objetivos-chave e dos fatores }\end{array}$ & 0 & 0 & 0 & 5 & 2 & \\
\hline & $\begin{array}{l}\text { críticos para que se tenha êxito e } \\
\text { uma análise dos fatores do } \\
\text { ambiente interno e externo (por } \\
\text { exemplo, análise SWOT) }\end{array}$ & $0,0 \%$ & $0,0 \%$ & $0,0 \%$ & $71,4 \%$ & $28,6 \%$ & 4,29 \\
\hline & & & & & & Média geral & 4,37 \\
\hline
\end{tabular}

Fonte: AUTOR, 2019.

Em sete das empresas pesquisadas existem normas de governança e orientações sobre sua aplicabilidade. Como resultado global, obteve-se a média geral de 4,37 pontos para os critérios de governança.

\subsubsection{Riscos}

Os resultados das pesquisas relacionadas com gestão de riscos dentro das organizações são relacionados na Tabela 2. 
Tabela 2

\section{Questionário Sobre Riscos}

\begin{tabular}{|c|c|c|c|c|c|c|c|}
\hline & $\begin{array}{l}\text { Gestão de riscos: questões } \\
\text { relacionadas }\end{array}$ & $\begin{array}{c}\text { Inexistent } \\
\mathrm{e}\end{array}$ & $\begin{array}{l}\text { Soment } \\
\text { e em } \\
\text { algumas } \\
\text { situaçõe } \\
\text { s }\end{array}$ & $\begin{array}{l}\text { Em alguns } \\
\text { departament } \\
\text { os da } \\
\text { organização }\end{array}$ & $\begin{array}{l}\text { Em vários } \\
\text { departament } \\
\text { os da } \\
\text { organização }\end{array}$ & $\begin{array}{l}\text { Em toda } \\
\text { organizaç } \\
\quad \text { ão }\end{array}$ & Média \\
\hline \multirow[b]{2}{*}{1} & \multirow{2}{*}{$\begin{array}{l}\text { A gestão de riscos adotada } \\
\text { pela empresa está alinhada ao } \\
\text { seu modelo de governança? }\end{array}$} & 0 & 0 & 2 & 3 & 2 & \multirow[b]{2}{*}{4,00} \\
\hline & & $0,0 \%$ & $0,0 \%$ & $28,6 \%$ & $42,9 \%$ & $28,6 \%$ & \\
\hline \multirow{2}{*}{2} & \multirow{2}{*}{$\begin{array}{l}\text { Há uma revisão periódica do } \\
\text { mapeamento de riscos? }\end{array}$} & 0 & 0 & 5 & 2 & 0 & \multirow{2}{*}{3,29} \\
\hline & & $0,0 \%$ & $0,0 \%$ & $71,4 \%$ & $28,6 \%$ & $0,0 \%$ & \\
\hline \multirow[b]{2}{*}{3} & \multirow{2}{*}{$\begin{array}{l}\text { Há notificação regular e } \\
\text { oportuna sobre as exposições } \\
\text { da organização a riscos, sobre } \\
\text { os riscos mais significativos e } \\
\text { respostas aos riscos? }\end{array}$} & 0 & 1 & 1 & 3 & 2 & \multirow[b]{2}{*}{3,86} \\
\hline & & $0,0 \%$ & $14,3 \%$ & $14,3 \%$ & $42,9 \%$ & $28,6 \%$ & \\
\hline \multirow[b]{2}{*}{4} & \multirow{2}{*}{$\begin{array}{l}\text { Há definição do nível de } \\
\text { maturidade para a gestão e } \\
\text { monitoramento de riscos da } \\
\text { empresa? }\end{array}$} & 1 & 0 & 1 & 3 & 2 & \multirow[b]{2}{*}{3,71} \\
\hline & & $14,3 \%$ & $\%$ & $14,3 \%$ & $42,9 \%$ & $28,6 \%$ & \\
\hline \multirow[b]{2}{*}{5} & \multirow{2}{*}{$\begin{array}{l}\text { Existem medidas de } \\
\text { desempenho claras (metas, } \\
\text { indicadores-chave e variações } \\
\text { aceitáveis) a fim de permitir a } \\
\text { identificação e avaliação dos } \\
\text { riscos e seus impactos nos } \\
\text { negócios da empresa? }\end{array}$} & 0 & 1 & 4 & 2 & 0 & \multirow[b]{2}{*}{3,14} \\
\hline & & $0,0 \%$ & $14,3 \%$ & $57,1 \%$ & $28,6 \%$ & $0,0 \%$ & \\
\hline \multirow[b]{2}{*}{6} & \multirow{2}{*}{$\begin{array}{l}\text { As medidas de desempenho } \\
\text { são divulgadas com clareza } \\
\text { suficiente, em termos } \\
\text { específicos e mensuráveis, } \\
\text { para a realização dos } \\
\text { objetivos-chave da empresa? }\end{array}$} & 0 & 0 & 1 & 5 & 1 & \multirow[b]{2}{*}{4,00} \\
\hline & & $0,0 \%$ & $0,0 \%$ & $14,3 \%$ & $71,4 \%$ & $14,3 \%$ & \\
\hline \multirow[b]{2}{*}{7} & \multirow{2}{*}{$\begin{array}{l}\text { Existem diretrizes sobre a } \\
\text { periodicidade que os riscos } \\
\text { devem ser identificados, } \\
\text { avaliados, tratados, } \\
\text { monitorados e comunicados } \\
\text { na empresa? }\end{array}$} & 0 & 0 & 4 & 3 & 0 & \multirow[b]{2}{*}{3,43} \\
\hline & & $0,0 \%$ & $0,0 \%$ & $57,1 \%$ & $42,9 \%$ & $0,0 \%$ & \\
\hline \multirow[b]{2}{*}{8} & \multirow{2}{*}{$\begin{array}{l}\text { A administração aloca } \\
\text { recursos suficientes e } \\
\text { apropriados na empresa: } \\
\text { pessoas, estruturas, sistemas } \\
\text { de TI, programas de } \\
\text { treinamento, métodos e } \\
\text { ferramentas para gerenciar } \\
\text { riscos considerando o } \\
\text { tamanho da empresa, a } \\
\text { relevância das áreas, funções } \\
\text { e atividades críticas? }\end{array}$} & 0 & 1 & 4 & 2 & 0 & \multirow[b]{2}{*}{3,14} \\
\hline & & $0,0 \%$ & $14,3 \%$ & $57,1 \%$ & $28,6 \%$ & $0,0 \%$ & \\
\hline \multirow[b]{2}{*}{9} & \multirow{2}{*}{$\begin{array}{l}\text { Os gestores são capacitados e } \\
\text { têm plena consciência de sua } \\
\text { propriedade e sua } \\
\text { responsabilidade pela } \\
\text { identificação e gerenciamento }\end{array}$} & 0 & 0 & 2 & 4 & 1 & \multirow[b]{2}{*}{3,86} \\
\hline & & $0,0 \%$ & $0,0 \%$ & $28,6 \%$ & $57,1 \%$ & $14,3 \%$ & \\
\hline
\end{tabular}


Oliveira, E. V., \& Zaidan, F. H. (2022, out./dez.). Implementação da modelagem da informação da construção (BIM) em projetos pesquisa e proposta de melhoria no contexto da governança, risco e conformidade (GRC)

\begin{tabular}{|c|c|c|c|c|c|c|c|}
\hline & $\begin{array}{l}\text { Gestão de riscos: questões } \\
\text { relacionadas }\end{array}$ & $\begin{array}{c}\text { Inexistent } \\
\mathrm{e}\end{array}$ & $\begin{array}{c}\text { Soment } \\
\text { e em } \\
\text { algumas } \\
\text { situaçõe } \\
\text { s }\end{array}$ & $\begin{array}{c}\text { Em alguns } \\
\text { departament } \\
\text { os da } \\
\text { organização }\end{array}$ & $\begin{array}{c}\text { Em vários } \\
\text { departament } \\
\text { os da } \\
\text { organização }\end{array}$ & $\begin{array}{l}\text { Em toda } \\
\text { organizaç } \\
\text { ão }\end{array}$ & Média \\
\hline & $\begin{array}{l}\text { dos riscos e dos controles } \\
\text { internos eficazes na empresa? }\end{array}$ & & & & & & \\
\hline \multirow{3}{*}{10} & \multirow{2}{*}{$\begin{array}{l}\text { Há análises de partes } \\
\text { interessadas (stakeholders) e } \\
\text { de seus interesses com a } \\
\text { utilização de matriz de } \\
\text { responsabilidades na } \\
\text { empresa? }\end{array}$} & 0 & 0 & 3 & 4 & 0 & \\
\hline & & $0,0 \%$ & $0,0 \%$ & $42,9 \%$ & $57,1 \%$ & $0,0 \%$ & 3,57 \\
\hline & & & & & & $\begin{array}{l}\text { Média } \\
\text { geral }\end{array}$ & 3,60 \\
\hline
\end{tabular}

Fonte: AUTOR, 2019.

Como resultado global, obteve-se a média geral de 3,60 pontos para os quesitos de organização relacionados riscos.

\subsubsection{Conformidade (compliance)}

Os resultados das pesquisas relacionados com conformidade e seus sistemas de auditoria e garantia de integridade dentro das organizações são relacionados na Tabela 3.

Tabela 3

\section{Questionário Sobre Conformidade}

\begin{tabular}{|c|c|c|c|c|c|c|c|c|}
\hline & $\begin{array}{l}\text { Conformidade (compliance): } \\
\text { questões relacionadas }\end{array}$ & Inexistente & $\begin{array}{l}\text { Somente } \\
\text { em } \\
\text { algumas } \\
\text { situações }\end{array}$ & $\begin{array}{l}\text { Em alguns } \\
\text { departamentos } \\
\text { da organização }\end{array}$ & $\begin{array}{l}\text { Emv } \\
\text { departa } \\
\text { da orga }\end{array}$ & $\begin{array}{l}\text { os } \\
\text { atos } \\
\text { ação }\end{array}$ & $\begin{array}{l}\text { Em toda } \\
\text { organização }\end{array}$ & Média \\
\hline & A empresa conhece a & 0 & 0 & 0 & 0 & 7 & & \\
\hline 1 & $\begin{array}{l}\text { legislação anticorrupção a } \\
\text { qual está sujeita? }\end{array}$ & $0,0 \%$ & $0,0 \%$ & $0,0 \%$ & $0,0 \%$ & $100,0 \%$ & $\%$ & 00 \\
\hline & Existe na empresa um & 0 & 0 & 0 & 1 & 6 & & \\
\hline 2 & $\begin{array}{l}\text { código de conduta ou } \\
\text { documentos correlatos que } \\
\text { descrevam as condutas } \\
\text { éticas que devem ser } \\
\text { observadas pelos } \\
\text { empregados próprios e/ou } \\
\text { terceirizados? }\end{array}$ & $0,0 \%$ & $0,0 \%$ & $0,0 \%$ & $14,3 \%$ & $85,7 \%$ & 4,8 & 86 \\
\hline & Existe na empresa um & 0 & 0 & 1 & 0 & 6 & & \\
\hline 3 & $\begin{array}{l}\text { programa de integridade } \\
\text { com adoção de política, } \\
\text { procedimentos e controles? }\end{array}$ & $0,0 \%$ & $0,0 \%$ & $14,3 \%$ & $0,0 \%$ & $85,7 \%$ & 4,7 & 71 \\
\hline & O programa de integridade & 0 & 0 & 0 & 2 & 5 & & \\
\hline 4 & $\begin{array}{l}\text { é estruturado com o } \\
\text { objetivo de detectar e sanar } \\
\text { desvios, fraudes, }\end{array}$ & $0,0 \%$ & $0,0 \%$ & $0,0 \%$ & $28,6 \%$ & $71,4 \%$ & 4,7 & 71 \\
\hline
\end{tabular}




\begin{tabular}{|c|c|c|c|c|c|c|c|c|}
\hline \multicolumn{2}{|c|}{$\begin{array}{l}\text { Conformidade (compliance): } \\
\text { questões relacionadas }\end{array}$} & \multirow[t]{2}{*}{ Inexistente } & \multirow[t]{2}{*}{$\begin{array}{l}\text { Somente } \\
\quad \text { em } \\
\text { algumas } \\
\text { situações }\end{array}$} & \multirow[t]{2}{*}{$\begin{array}{l}\text { Em alguns } \\
\text { departamentos } \\
\text { da organização }\end{array}$} & \multicolumn{2}{|c|}{$\begin{array}{c}\text { Em vários } \\
\text { departamentos } \\
\text { da organização }\end{array}$} & $\begin{array}{l}\text { Em toda } \\
\text { organização }\end{array}$ & \multirow[t]{2}{*}{ Média } \\
\hline & $\begin{array}{l}\text { irregularidades e atos ilícitos } \\
\text { praticados? }\end{array}$ & & & & & & & \\
\hline \multirow[b]{2}{*}{5} & \multirow{2}{*}{$\begin{array}{l}\text { Existe na empresa uma } \\
\text { estrutura de prestação de } \\
\text { contas com } \\
\text { responsabilidade } \\
\text { (accountability) e } \\
\text { responsabilidade } \\
\text { corporativa (compliance) }\end{array}$} & 0 & 0 & 1 & 3 & 3 & & \multirow[b]{2}{*}{4,29} \\
\hline & & $0,0 \%$ & $0,0 \%$ & $14,3 \%$ & $42,9 \%$ & $42,9 \%$ & & \\
\hline \multirow[b]{2}{*}{6} & \multirow{2}{*}{$\begin{array}{l}\text { Existe na empresa } \\
\text { procedimentos que } \\
\text { assegurem a interrupção e } \\
\text { correção de irregularidades } \\
\text { ou infrações detectadas, } \\
\text { bem como a remediação } \\
\text { dos danos gerados? }\end{array}$} & 0 & 0 & 0 & 3 & 4 & & \multirow[b]{2}{*}{4,57} \\
\hline & & $0,0 \%$ & $0,0 \%$ & $0,0 \%$ & $42,9 \%$ & $57,1 \%$ & & \\
\hline \multirow[b]{2}{*}{7} & \multirow{2}{*}{$\begin{array}{l}\text { Existem normativos internos } \\
\text { de Due Dilligence (processo } \\
\text { exigente de auditoria feito } \\
\text { para investigar e } \\
\text { diagnosticar a gestão } \\
\text { financeira, contábil e fiscal, } \\
\text { trabalhista, previdenciária, } \\
\text { ambiental, jurídica, } \\
\text { imobiliária, de prioridade } \\
\text { intelectual e até mesmo } \\
\text { tecnológica da empresa) } \\
\text { para a avaliação da } \\
\text { reputação, idoneidade e das } \\
\text { práticas de combate à } \\
\text { corrupção de terceiros e } \\
\text { parceiros operacionais? }\end{array}$} & 0 & 1 & 3 & 2 & 1 & & \multirow[b]{2}{*}{3,43} \\
\hline & & $0,0 \%$ & $14,3 \%$ & $42,9 \%$ & $28,6 \%$ & $14,3 \%$ & & \\
\hline \multirow[b]{2}{*}{8} & \multirow{2}{*}{$\begin{array}{l}\text { São estipuladas pela } \\
\text { empresa em seus contratos } \\
\text { penalidades a serem } \\
\text { aplicadas a fornecedores e } \\
\text { empresas subcontratadas } \\
\text { que descumprirem normas } \\
\text { de ética e integridade? }\end{array}$} & 1 & 1 & 2 & 2 & 1 & & \multirow[b]{2}{*}{3,14} \\
\hline & & $14,3 \%$ & $14,3 \%$ & $28,6 \%$ & $28,6 \%$ & $14,3 \%$ & & \\
\hline \multirow[b]{2}{*}{9} & \multirow{2}{*}{$\begin{array}{l}\text { Estão disponibilizadas em } \\
\text { sítio eletrônico da empresa } \\
\text { a identificação e a função } \\
\text { de seus principais } \\
\text { executivos e dirigentes? }\end{array}$} & 2 & 2 & 0 & 2 & 1 & & \multirow[b]{2}{*}{2,71} \\
\hline & & $28,6 \%$ & $28,6 \%$ & $0,0 \%$ & $28,6 \%$ & $14,3 \%$ & & \\
\hline \multirow{3}{*}{10} & \multirow{3}{*}{$\begin{array}{l}\text { Existe na empresa estrutura } \\
\text { hierárquica definida para } \\
\text { coordenar implementar o } \\
\text { programa de integridade? }\end{array}$} & 0 & 0 & 0 & 3 & 4 & & \multirow[b]{2}{*}{4,57} \\
\hline & & $0,0 \%$ & $0,0 \%$ & $0,0 \%$ & $42,9 \%$ & $57,1 \%$ & & \\
\hline & & & & & & $\begin{array}{l}\text { Média } \\
\text { geral }\end{array}$ & & 20, \\
\hline
\end{tabular}

Fonte: AUTOR, 2019. 
Como resultado global, obteve-se a média geral de 4,20 pontos para os critérios estrutura e monitoramento relacionados com a conformidade e das empresas consultadas.

\subsection{A pesquisa sobre o BIM}

Para atingir os objetivos deste estudo procurou-se conhecer os benefícios do BIM aplicados em empresas de engenharia durante a execução do ciclo regulador da DSR. Todavia, a pesquisa do BIM se baseou na interpretação de dados extraídos dos estudos realizados por Brito e Ferreira (2015), cujo modelo apresentou a suficiência das informações almejadas, inclusive com base na seleção dos artefatos apresentados nesta pesquisa. A Tabela 4 mostra os maiores e os menores graus de importância e aplicabilidade do BIM para cada potencialidade avaliada, indicando o IIR, a média, o desvio padrão e qual subgrupo obteve esses valores.

\section{Tabela 1}

Maiores graus de importância e aplicabilidade das potencialidades por subgrupos

\begin{tabular}{|c|c|c|c|c|c|c|c|c|}
\hline \multirow{2}{*}{ Potencialidades } & \multicolumn{3}{|c|}{ Maior grau de importância } & \multirow{2}{*}{ Amostra } & \multicolumn{3}{|c|}{ Maior aplicabilidade } & \multirow{2}{*}{ Amostra } \\
\hline & IIR & Média & Desvpad & & IIR & Média & Desvpad & \\
\hline $\begin{array}{l}\text { Redução do esforço } \\
\text { na visualização e } \\
\text { interpretação mental }\end{array}$ & 0,92 & 4,60 & 0,55 & $\begin{array}{l}5 \text { (Projeto e não } \\
\text { conhece o BIM } \\
\text { ou conhece e } \\
\text { nunca utilizou). }\end{array}$ & 0,89 & 4,44 & 0,53 & $\begin{array}{l}9 \text { (Projeto com } \\
\text { pós-graduação, } \\
\text { mestrado, } \\
\text { doutorado ou } \\
\text { pós-doutorado). }\end{array}$ \\
\hline $\begin{array}{l}\text { Identificação de } \\
\text { conflitos de espaço e } \\
\text { tempo }\end{array}$ & 0,97 & 4,83 & 0,41 & $\begin{array}{l}6 \text { (Arquiteto com } \\
\text { mestrado, } \\
\text { doutorado ou } \\
\text { pós-doutorado). }\end{array}$ & 0,93 & 4,67 & 0,52 & $\begin{array}{l}6 \text { (Arquiteto com } \\
\text { mestrado, } \\
\text { doutorado ou } \\
\text { pós-doutorado). }\end{array}$ \\
\hline $\begin{array}{l}\text { Inserção de } \\
\text { equipamentos, } \\
\text { elementos de } \\
\text { canteiro e recursos }\end{array}$ & 0,93 & 4,67 & 0,52 & $\begin{array}{l}6 \text { (Arquiteto com } \\
\text { mestrado, } \\
\text { doutorado ou } \\
\text { pós-doutorado). }\end{array}$ & 0,87 & 4,33 & 0,52 & $\begin{array}{l}6 \text { (Arquiteto com } \\
\text { mestrado, } \\
\text { doutorado ou } \\
\text { pós-doutorado). }\end{array}$ \\
\hline $\begin{array}{l}\text { Apoio no } \\
\text { sequenciamento e } \\
\text { conformação ideal do } \\
\text { cronograma }\end{array}$ & 0,93 & 4,63 & 0,52 & $\begin{array}{l}8 \text { (Pesquisa e } \\
\text { Ensino com } \\
\text { doutorado ou } \\
\text { pós-doutorado). }\end{array}$ & 0,88 & 4,38 & 0,52 & $\begin{array}{l}8 \text { (Pesquisa e } \\
\text { Ensino com } \\
\text { doutorado ou } \\
\text { pós-doutorado). }\end{array}$ \\
\hline $\begin{array}{l}\text { Transmissão de } \\
\text { impactos devido a } \\
\text { mudanças no } \\
\text { planejamento }\end{array}$ & 0,93 & 4,67 & 0,52 & $\begin{array}{l}6 \text { (Construção e } \\
\text { possui somente } \\
\text { graduação). }\end{array}$ & 0,84 & 4,22 & 0,44 & $\begin{array}{l}9 \text { (Projeto e } \\
\text { possui somente } \\
\text { graduação). }\end{array}$ \\
\hline $\begin{array}{l}\text { Integração e } \\
\text { comunicação entre } \\
\text { todos os envolvidos } \\
\text { no projeto }\end{array}$ & 0,96 & 4,80 & 0,45 & $\begin{array}{l}5 \text { (Projeto e não } \\
\text { conhece o BIM } \\
\text { ou conhece e } \\
\text { nunca utilizou). }\end{array}$ & 0,92 & 4,60 & 0,55 & $\begin{array}{l}\text { 5(Gerenciamento } \\
\text { com mestrado, } \\
\text { doutorado ou } \\
\text { pós-doutorado). }\end{array}$ \\
\hline
\end{tabular}

Fonte: BRITO; FERREIRA, 2015. 
O BIM é exigido pelo governo de vários países. No Brasil, a sua utilização começa a ser promovida pelo setor público, que visualiza na tecnologia BIM potencial para aumentar a transparência e diminuir a corrupção nas obras públicas. Daí a importância de as empresas estarem bem estruturadas e priorizarem a implementação do BIM em seus processos de engenharia, já que podem obter ganhos com a padronização de cronograma e orçamento, com facilidade de alterações automáticas quando são feitos ajustes de projetos.

\subsection{Avaliação dos resultados obtidos e possibilidades de ganhos}

A Figura 4 indica as principais deficiências que foram encontradas nas sete empresas de engenharia pesquisadas, segundo a ótica da governança, gestão de riscos e conformidade. Em contrapartida, a mesma figura indica oportunidades de ganhos, com base em estudos da literatura e pesquisas relacionados com a implementação do BIM. Como resultado, busca-se indicar como o BIM pode melhorar os resultados e mitigar as lacunas observadas em GRC.

Os resultados indicaram lacunas em termos de GRC, onde se observa que, em governança, a principal atividade de melhoria está relacionada à eficácia dos processos de gerenciamento dos riscos. Quanto à gestão de riscos, os pontos de melhorias estão relacionados às revisões periódicas, medidas de desempenho aliadas aos impactos nos negócios da empresa, periodicidade de avaliação e monitoramento dos riscos e alocação de recursos para gerenciamento dos riscos.

Quanto à conformidade, os aspectos relacionados com normativos para avaliação de reputação e práticas de combate à corrupção de parceiros, penalidades a fornecedores e identificação dos principais executivos em sítio da internet são os principais procedimentos a serem melhorados. 
Figura 4

Lacunas no Sistema de GRC em Empresas de Engenharia e Oportunidades de Melhorias e Ganhos com a Implementação do BIM

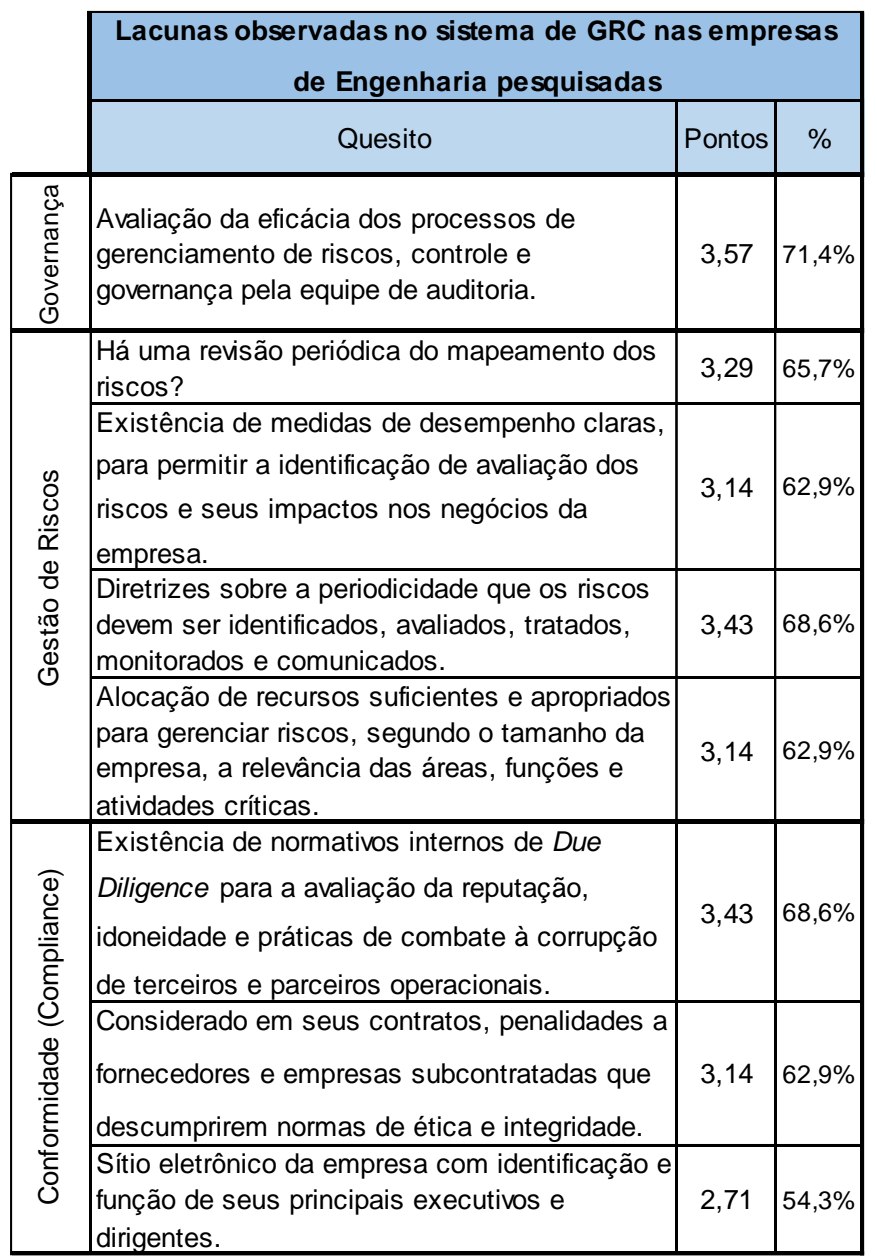

Fonte: AUTOR, 2019.

\begin{tabular}{|c|c|c|}
\hline & \multicolumn{2}{|c|}{$\begin{array}{l}\text { Principais oportunidades de melhorias e ganhos com a } \\
\text { implementação do BIM }\end{array}$} \\
\hline & $\begin{array}{c}\text { Classifi- } \\
\text { cação }\end{array}$ & Ganhos observados \\
\hline \multirow{5}{*}{ 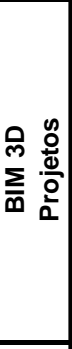 } & 1 & $\begin{array}{l}\text { Identificação de possíveis conflitos e interferências de } \\
\text { espaço e tempo. }\end{array}$ \\
\hline & 2 & $\begin{array}{l}\text { Integração e comunicação entre todos os envolvidos } \\
\text { no projeto. }\end{array}$ \\
\hline & 3 & $\begin{array}{l}\text { Redução do esforço na visualização e interpretação } \\
\text { mental. }\end{array}$ \\
\hline & 4 & Redução da duração geral do projeto. \\
\hline & 5 & $\begin{array}{l}\text { Redução das interferências de espaço e tempo } \\
\text { durante a construção. }\end{array}$ \\
\hline \multirow{6}{*}{ 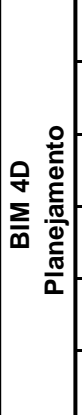 } & 1 & Redução de erros e omissões. \\
\hline & 2 & Colaboração entre proprietários e firmas de projeto. \\
\hline & 3 & Melhora da imagem organizacional. \\
\hline & 4 & Redução do retrabalho. \\
\hline & 5 & Redução e melhor controle de custos. \\
\hline & 6 & ação geral \\
\hline \multirow{3}{*}{ 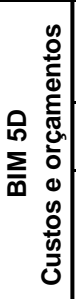 } & 1 & $\begin{array}{l}\text { Fase de modelagem, passando pela extração de } \\
\text { dados do modelo, a indexação dos dados } \\
\text { quantitativos aos custos fornecidos. }\end{array}$ \\
\hline & 2 & $\begin{array}{l}\text { Automação dos processos de levantamento de } \\
\text { quantidades. }\end{array}$ \\
\hline & 3 & $\begin{array}{l}\text { Ao alterar-se um elemento no modelo, } \\
\text { automaticamente alterar-se as quantidades vinculadas } \\
\text { a este elemento, atualizando o orçamento. }\end{array}$ \\
\hline
\end{tabular}




\subsection{Discussão}

As lacunas observadas em GRC estão indicadas de forma objetiva no quadro à esquerda da Figura 4, e no quadro à direita estão relacionadas as principais oportunidades de ganhos com a implementação do BIM. Ou seja, as falhas identificadas nas empresas, relacionadas com a estrutura de GRC, podem ser mitigadas com a adoção das dimensões do BIM.

Em contrapartida, os principais ganhos com a implementação do BIM poderão compensar as lacunas que podem ser observadas, como consequência do baixo grau de aderência aos critérios e políticas de governança, gestão dos riscos e conformidade. Os resultados identificados no Figura 5 tomam como base os principais benefícios segundo pesquisa exploratória da literatura e pesquisa nas empresas de engenharia indicadas neste estudo.

Enquanto a Figura 4 indica deficiências em GRC e relaciona as oportunidades de ganhos com a implementação do BIM, a Figura 5 tem como objetivo indicar os principais ganhos relacionados neste estudo e os impactos que estes têm em termos de GRC. Em suma, ambas as figuras comprovam a eficácia da implementação do BIM e indicam ganhos de forma antagônica, porém complementares, e objetivam dar segurança para as análises de decisões, eliminando as dúvidas quanto a sua implementação.

Figura 5

Relação entre os principais ganhos com a implementação do BIM e seus impactos de melhoria em GRC

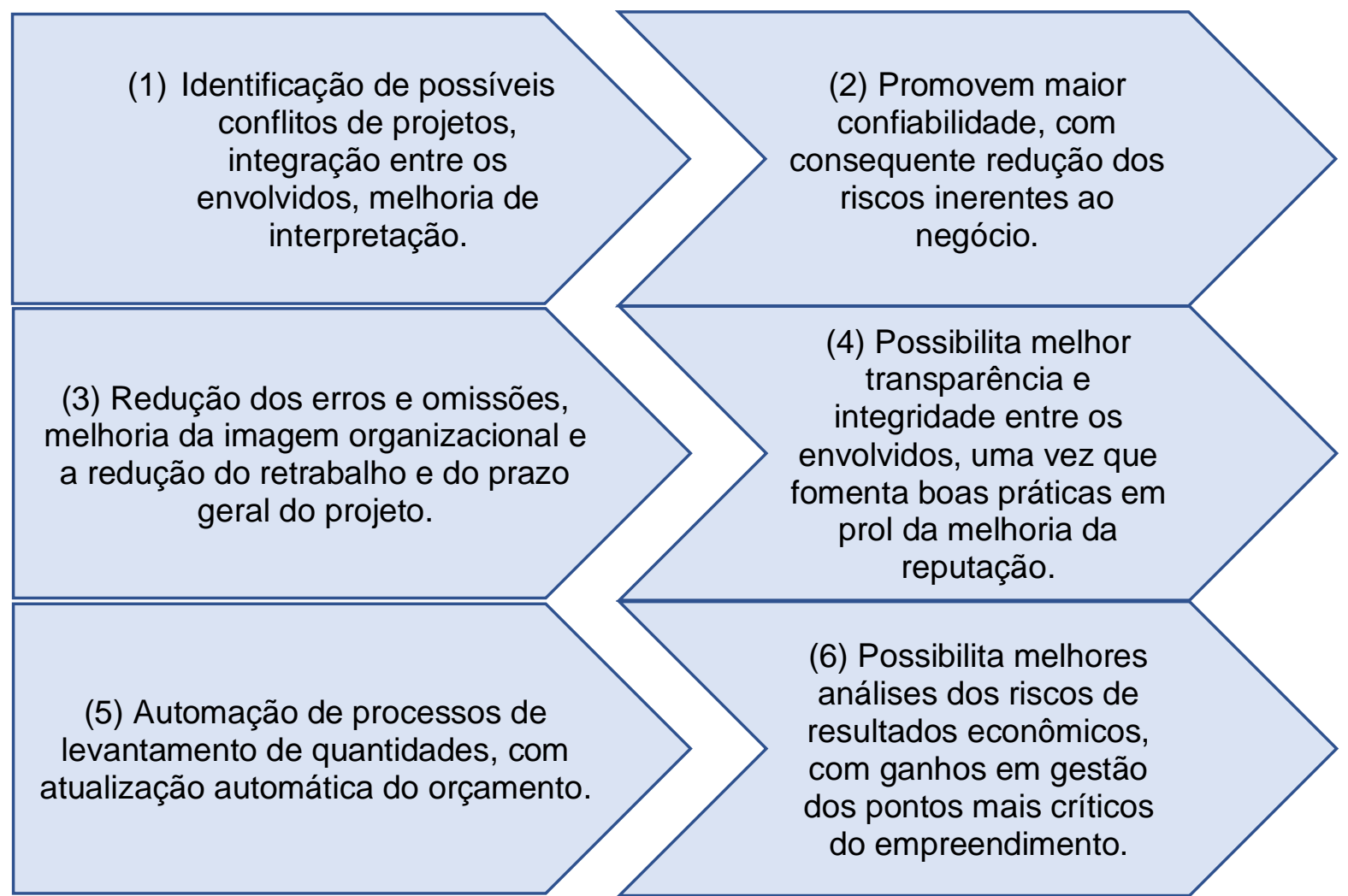




\section{Legenda:}

(1) Compilado das conclusões da pesquisa sobre o BIM, item 5.2, baseada nos resultados extraídos dos estudos realizados por Brito e Ferreira (2015).

(2) A pesquisa sobre GRC, item 5.1, indica que, em termos de governança, dentre as sete empresas entrevistadas, o gerenciamento de riscos apresentou menor nota de avaliação e, portanto, como ponto de atenção a ser tratado.

(3) Segundo item 3.4, extraído da descrição do BIM dada por Menegaro e Piccinini (2017).

(4) Os resultados das pesquisas relacionadas com conformidade, segundo conclusões indicadas no item 5.1.2.3, as políticas em prol da ética e integridade são indicadas com ponto de atenção.

(5) No item 5.1, conforme cita Pelliza (2018), outra vantagem do BIM 5D é, ao se alterar um elemento no modelo, automaticamente as quantidades vinculadas a este elemento são ajustadas e o orçamento é atualizado.

(6) Como resultado da pesquisa sobre gestão de riscos, uma das conclusões do item 5.1.2.2 indica a necessidade de se incrementar a gestão de métodos e ferramentas para gerenciar riscos, considerando o tamanho da empresa, a relevância das áreas, funções e atividades críticas.

\section{Conclusões}

A necessidade de redimensionamento estrutural em empresas de engenharia, decorrente de tempos de crise, ocasionou a mudança nas estratégias de gestão dos negócios. Além disso, operações anticorrupção, contribuiu para o temor em arriscar no meio da corrupção e direcionou o foco para a ética profissional, que privilegia a honestidade e a moralidade em sua atuação.

Em decorrência disto, o BIM passou a ser adotado pelas empresas de engenharia. Nesse sentido, em toda a cadeia produtiva e de gestão a visão de mercado passou a ser focada em políticas de governança, gestão de riscos e conformidade eficazes. A adoção dessas políticas está evidente nos resultados da pesquisa em GRC feita com principais executivos de algumas empresas do ramo, relatadas neste trabalho.

Como resultado da pesquisa ficou evidente falhas na gestão de riscos, o que pode resultar em perdas de resultados nos negócios de engenharia. Como busca da excelência e melhoria nos resultados de qualidade de projetos, cumprimento das metas de prazos e custos, a proposta apresentada é a implementação da modelagem da informação da construção, BIM.

Este trabalho buscou apresentar contribuições referentes ao conhecimento da visão da construção civil brasileira sobre potencialidades, estratégias para representação e análise, além das possibilidades de adoção dos modelos BIM nas dimensões 3D, 4D e 5D aos projetos, planejamento e custos de obras. Consequentemente poderá subsidiar uma melhor compreensão na percepção dos usuários e possibilitar uma melhor identificação de suas necessidades.

Além disso, as pesquisas apresentadas indicaram as vantagens da implementação do BIM e foram feitas analogias aos resultados aplicados em empresas bem estruturadas em GRC. O modelo BIM 
é um instrumento de apoio e suporte, que pode ser usado pelos gestores de empresa, para colaborar no combate à corrupção.

Conclui-se que para a mitigação dos riscos decorrentes de falhas em processos em empresas de engenharia, tal ocorrência é possível por meio da implementação do BIM. Além de que o melhor entendimento da adoção dos processos relacionados ao GRC em empresas de engenharia, segundo pesquisa, poderá possibilitar a compreensão da predisposição e das lacunas relacionadas aos procedimentos e políticas em governança, gestão de riscos e conformidade. Ademais, que haverá ganhos em termos de importância e aplicabilidade em projetos e construções de engenharia com o BIM 4D, em termos de planejamento e com o BIM 5D em orçamentos e gestão de custos.

\section{Referências}

ABNT. Associação Brasileira de Normas Técnicas. ABNT/CEE-309. NBR 19601: sistemas de gestão de compliance - requisitos. Rio de Janeiro, 2018.

BRITO, Douglas Malheiro de; FERREIRA, Emerson de Andrade Marques. Avaliação de estratégias para representação e análise do planejamento e controle de obras utilizando modelos BIM 4D. Ambiente Construído, Porto Alegre, v. 15, n. 4, p. 203-223, out./dez. 2015. Disponível em: http://dx.doi.org/10.1590/s1678-86212015000400047. Acesso em: 22 jul. 2019.

CERRAO, Natalia Gallo; CASTRO, Fabiano Ferreira; JESUS, Ananda Fernanda. O método de revisão sistemática da literatura (RS) na área da Ciência da Informação no Brasil: análise de dados de pesquisa. Informação \& Tecnologia (ITEC), Marília/João Pessoa, v. 5, n. 1, p. 105-116, jan./jun. 2018. Disponível em:

http://www.periodicos.ufpb.br/ojs/index.php/itec/article/view/38083/22112. Acesso em: 23 jul. 2019.

EASTMAN, C. et al. BIM handbook: a guide to building information modeling for owners, managers, designers, engineers, and contractors. New Jersey: Jhon Wiley \& Sons Inc., 2008.

FORMOSO, Carlos T. Planejamento e controle da produção em empresas de construção. 2001. Tese (Doutorado em Engenharia Civil) - Universidade Federal do Rio Grande do Sul, UFRS, Porto Alegre, 2001. Disponível em: https://docplayer.com.br/1046206-Planejamento-e-controle-daproducao-em-empresas-de-construcao.html. Acesso em: 08 fev. 2019.

GELLERMAN, Saul William. Why ethical people make unethical choices. Harvard Business Review (Online) [online]. 1986. Disponível em: https://hbr.org/1986/07/why-good-managers-makebad-ethical-choices. Acesso em: 25 jan. 2019.

LACERDA, Daniel Pacheco; DRESCH, Aline; PROENÇA, Adriano; ANTUNES JÚNIOR, José Antonio Valle. Design Science Research: método de pesquisa para a engenharia de produção. Gest. Prod., São Carlos, v. 20, n. 4, p. 741-761, 2013. Disponível em: http://www.scielo.br/scielo.php?script=sci_arttext\&pid=S0104-530X2013000400001. Acesso em: 20 fev. 2019. 
MENEGARO, Bruna Ferreira; PICCININI, Ângela Costa. Aplicação da metodologia BIM (Building Information Modeling) no processo de projeto, com foco em compatibilização. Universidade do Extremo Sul Catarinense, 2017. Disponível em: http://repositorio.unesc.net/bitstream/1/5878/1/BrunaFerreiraMenegaro.pdf. Acesso em: 13 fev. 2019.

PELLIZA, Guilherme. Porque e como fazer orçamento de obra em BIM. BIM na prática, 2018.Disponível em: https://bimnapratica.com/blog/orcamento-de-obra-em-bim. Acesso em: 5 fev. 2019.

RAMOS, Carlos Eduardo da Silva; RODRIGUES, Leandro Ferreira Pacheco; MELLO, Luiz Carlos Brasil de Brito. Aplicações da Indústria 4.0 na Construção Civil - Uma Revisão Narrativa. 2018. VII Congresso Brasileiro de Engenharia de Produção.

RODAS, Inês Aidé Ribeiro de Freitas. Aplicação da metodologia BIM na gestão de edifícios. 2015. Dissertação (Mestrado em Engenharia Civil) - Faculdade de Engenharia, Universidade do Porto, Porto, 2015. Disponível em: https://sigarra.up.pt/reitoria/pt/pub_geral.show_file?pi_doc_id=31501. Acesso em: 13 fev. 2019.

RODRIGUES, Priscilla Borges de Freitas; MACHADO, Ricardo Luiz; MENDES JÚNIOR, Ricardo; ROMAGNOLI, Larsson Diogo Seabra Coelho. Uma proposta de integração do modelo BIM ao sistema last planner. Ambiente Construído, Porto Alegre, v. 18, n. 4, p. 301-317, out./dez. 2018. ISSN 1678-8621 Associação Nacional de Tecnologia do Ambiente Construído. Disponível em: http://dx.doi.org/10.1590/s1678-86212018000400306. Acesso em: 13 fev. 2019.

VICENTE, Pedro Filipe Oliveira; SILVA, Miguel Mora da. Advanced information systems engineering: 23a Conferência Internacional. In: A Conceptual Model for Integrated Governance, Risk and Compliance. CAISSE 2011, Londres, Reino Unido, 20 a 24 de junho de 2011. Anais (pp.199213). Disponível em:

https://www.researchgate.net/publication/220921351_A_Conceptual_Model_for_Integrated _Governance_Risk_and_Compliance. Acesso em: 07 fev. 2019.

TEIXEIRA, Edson Sidnei Maciel; MELIM, José Maria. Proposta de cálculo de graus de maturidade da cultura Lean. IV CONGRESSO DE SISTEMAS LEAN 23 E 24 DE MAIO DE 2014. Porto Alegre, UFRGS, 2014. Disponível em:

https://www.researchgate.net/profile/Edson_Teixeira/publication/263465271_Proposta_de_ Calculo_de_Graus_de_Maturidade_da_Cultura_Lean/links/0a85e53aeace579245000000.pdf. Acesso em: 29 jun. 2019.

WHITTEMORE, Robin; CHASE, Susan k.; MANDLE, Carol Lynn. Validity in Qualitative Research. Qualitative Health Research, v. 11, n. 4, p. 522-537, 2001. Disponível em: http://citeseerx.ist.psu.edu/viewdoc/download;jsessionid=4586DF58E65BDB74AC1676AFC18 3BB06?doi=10.1.1.620.410\&rep=rep1\&type=pdf. Acesso em: 21 jul. 2019.

WIERINGA, R. Design science as nested problem solving. In: INTERNATIONAL CONFERENCE ON DESIGN SCIENCE RESEARCH IN INFORMATION SYSTEMS AND TECHNOLOGY, 4, 2009, Philadelphia. Proceedings [...]. Philadelphia, PA, USA ACM, 2009. 